\title{
Test bench for pneumatic clutch actuators
}

\author{
Stanowisko do testowania siłownilków pneumatycznych
} MAREK STEMBALSKI
PIOTR DYCHOWSKI*

A test bench for pneumatic actuators for controlling the clutch in trucks with automatic gearbox is presented. The mechanical part of the station is shown. The individual steps of the testing process of this actuator as well as exemplary test results carried out at the described station were discussed. KEYWORDS: pneumatic actuator, testing proces of product, clutch control

Przedstawiono stanowisko do testowania siłowników pneumatycznych służących do sterowania sprzęgłem w pojazdach ciężarowych z automatyczną skrzynią biegów. Pokazano część mechaniczna stanowiska. Omówiono poszczególne kroki procesu testowania siłownika oraz przykładowe wyniki testów przeprowadzonych na opisanym stanowisku.

SŁOWA KLUCZOWE: siłownik pneumatyczny, proces testowania produktu, sterowanie sprzęgłem

\section{Wprowadzenie}

Siłowniki elektropneumatyczne stosowane w branży automotive służą do wielu zadań, m.in. do sterowania układem wysprzęglania w pojazdach ciężarowych [1-7]. W zakładach produkujących takie siłowniki potrzebne są stanowiska testowe. Po wytworzeniu danego wyrobu należy bowiem sprawdzić, czy spełnia on zadane wymagania. Testowanie produktów jest bezpośrednio związane ze specyfikacją wyrobu.

Prezentowane w pracy stanowisko testowe powstało z uwagi na fakt, że poprzednio wykorzystywane stanowisko przestało poprawnie funkcjonować. Poziom powtarzalności przeprowadzanych testów był niewystarczający. Zaprojektowanie i wykonanie nowego stanowiska testowego mogłoby znacznie skrócić czas procesu testowania i tym samym poprawić wydajność produkcji siłowników elektropneumatycznych.

\section{Testowany siłownik}

Na rys. 1 pokazano testowany siłownik elektropneumatyczny. Ma on dwa przyłącza pneumatyczne oraz dwa elektryczne. Port pneumatyczny P1 służy do zasilania, natomiast P2 - do odpowietrzania. Port elektryczny sześciopinowy odpowiada za sterowanie elektrozaworem z czterema cewkami, a port elektryczny dwupinowy - za odczyt wartości induktancji z czujnika, będącego częścią siłownika. Ciśnienie podawane jest na port P1. Zasada działania portu P2 jest natomiast podobna do działania wentylu.

Elektrozawór z czterema cewkami steruje układem pneumatycznym siłownika. Sterowanie elektrozaworem jest realizowane przez podanie sygnału na sześciopinowy port elektryczny Dzięki temu siłownik może pracować w dwie strony.

\section{DOI: https://doi.org/10.17814/mechanik.2019.11.105}

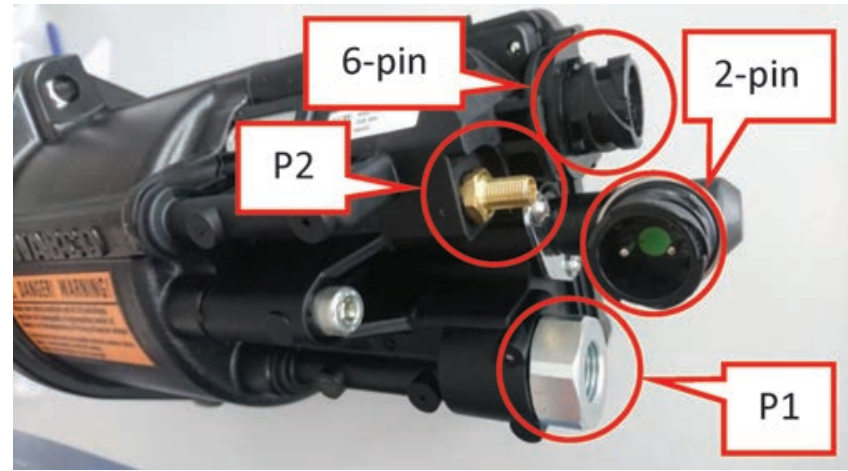

Fig. 1. View of the actuator with electrical and pneumatic connections Rys. 1. Widok siłownika wraz z przyłączami elektrycznymi i pneumatycznymi

\section{Projekt stanowiska}

Na pierwszym etapie projektowania części mechanicznej stanowiska opracowano sposób automatycznego podłączenia przyłączy pneumatycznych i elektrycznych testowanego siłownika oraz określono orientację tłoka względem płyty stanowiska i umiejscowienie serwonapędu służącego do wstępnego testu siłownika. Polega on na trzykrotnym dojeździe popychacza do pozycji maksymalnego wysuwu i wsunięciu tłoka siłownika.

Stanowisko testowe (rys. 2) zawiera: gniazdo mechaniczne służące do blokowania siłownika 1, ramię z przyłączami 2 oraz zespół popychacza 3 z serwonapędem 4. Do części mechanicznej należy zaliczyć także płytę 5 (na której opiera się cała komora testowa) oraz ramę 6 , stanowiące szkielet całego stanowiska.

Istotnym elementem projektowanego stanowiska był zespół popychacza (rys. 3), który generuje siłę oporu na tłoczysku siłownika i tym samym odpowiada za przemieszczenie tłoka.

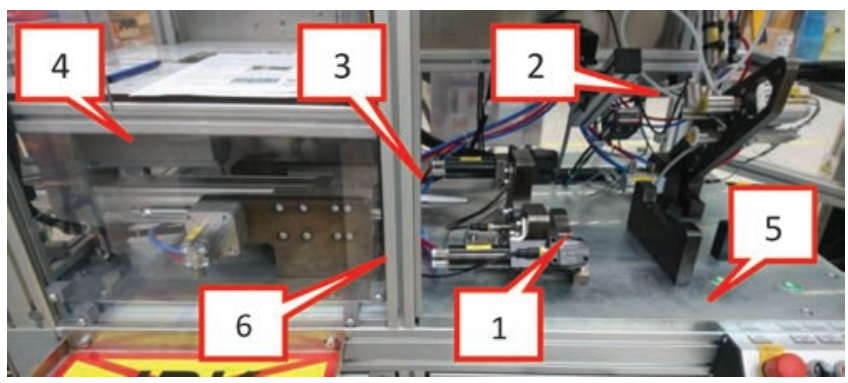

Fig. 2. Main elements of the mechanical part of the station: 1 - socket for mechanical, 2 - arm with connections, 3 - pusher assembly, 4 - servomotor, 5 - plate, 6 - frame

Rys. 2. Główne elementy części mechanicznej stanowiska: 1 - gniazdo mechaniczne, 2 - ramię z przyłączami, 3 - zespół popychacza, 4 - serwomotor, 5 - płyta, 6 - rama

\footnotetext{
* Dr inż. Marek Stembalski, marek.stembalski@pwr.edu.pl, https://orcid.org/0000-0002-0801-690X - Politechnika Wrocławska, Wydział Mechaniczny, Katedra Obrabiarek i Technologii Mechanicznych, Wrocław, Polska

Mgr inż. Piotr Dychowski, 222821@student.pwr.edu.pl - Politechnika Wrocławska
} 
Zastosowanie czujnika tensometrycznego działającego w pełnym mostku Wheatstone'a pozwoliło na pomiar tej siły (rys. 3). Umiejscowienie czujnika zaznaczono czerwonym okręgiem.

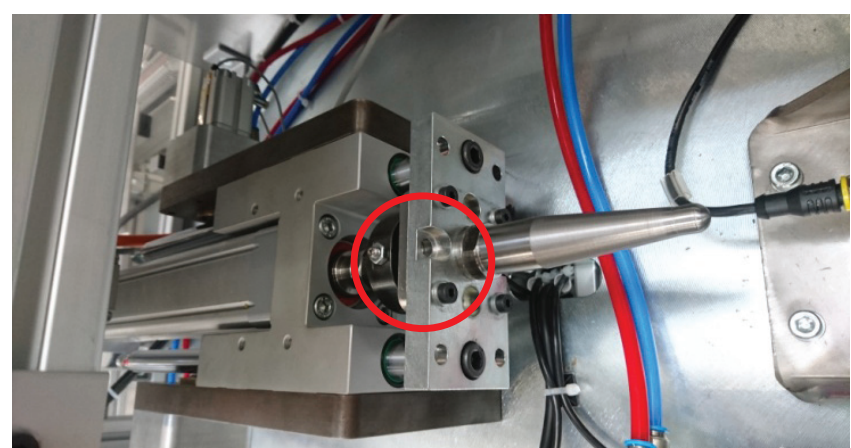

Fig. 3. Pusher assembly with a force sensor mounted on the platform Rys. 3. Zespół popychacza wraz z czujnikiem siły, zamontowany na platformie

Na kolejnym etapie opracowano gniazdo (rys. 4), którego zadaniem jest jednoznaczne ustalenie wyrobu, aby zapewnić powtarzalność wyników pomiaru. W jego skład wchodzą: trzy bloki 1 o specjalnej geometrii uwarunkowanej geometrią wyrobu, kątownik 2 , łączący dodatkowo pierwszy (od strony zespołu popychacza) blok z platformą, oraz kątowniki 3 do montażu siłowników wykorzystywanych do mocowania produktu w gnieździe.

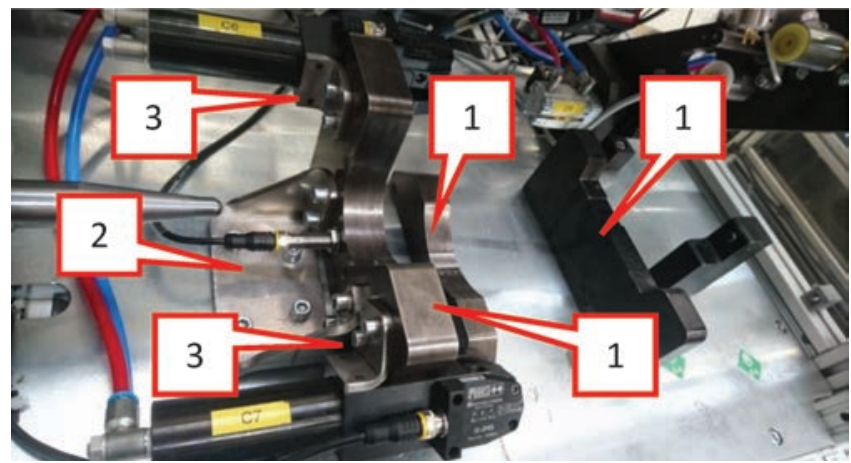

Fig. 4. Composition of the mechanical socket: 1 - socket block, 2 - angle bracket connecting the first block to the plate, 3 - angle brackets for mounting the cylinder blocking the product

Rys. 4. Skład gniazda mechanicznego: 1 - blok gniazda, 2 - kątownik łączący pierwszy blok z płytą, 3 - kątowniki do montażu siłowników blokujących produkt

Ostatnim ważnym elementem stanowiska jest ramię (rys. 5) z przyłączami pneumatycznymi P1 i P2. Dodatkowo zawiera ono dwa przyłącza elektryczne: sześcio- oraz dwupinowe.

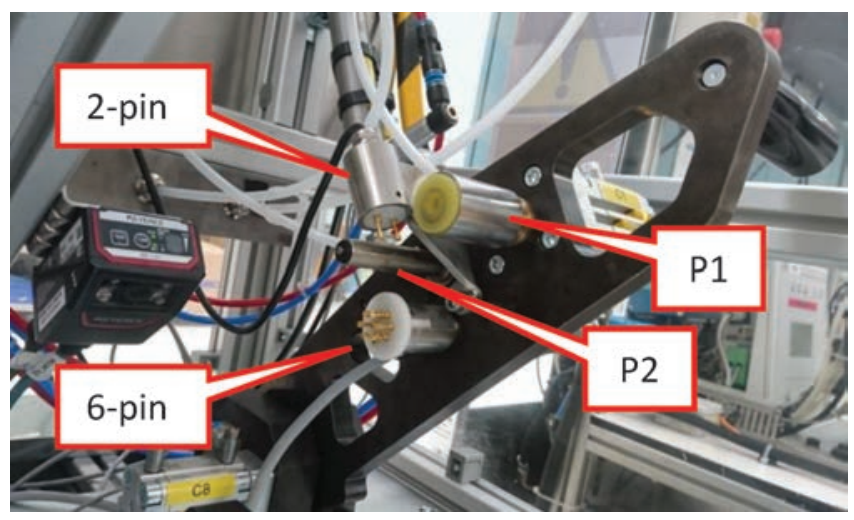

Fig. 5. Arm with electrical and pneumatic connections

Rys. 5. Ramię z przyłączami elektrycznymi i pneumatycznymi
Za poprawne blokowanie testowanego siłownika oraz przemieszczanie przyłączy pneumatycznych oraz ruch ramienia odpowiedzialnych jest dziewięć siłowników pneumatycznych (rys. 6) oznaczonych symbolami C1-C9. Siłowniki C1-C3 służą do sterowania przyłączami P1 i P2 oraz gniazdem sześciopinowym. Siłowniki C4-C5 służą do blokowania zespołu popychacza w testach zaworu bezpieczeństwa, szczelności badanego siłownika oraz szczelności podłączeń P1 i P2. Kolejne dwa siłowniki C6 i C7 - służą do zamocowania testowanego wyrobu względem gniazda mechanicznego. Funkcją siłownika C8 jest blokowanie ramienia z przyłączami w jego dolnym położeniu. Ma to na celu unieruchomienie ramienia podczas procedury testowania. Praca tego siłownika występuje w zasadzie tylko w dwóch momentach - podczas uzbrajania stanowiska bezpośrednio przed przystąpieniem do procedury testowania (można to uznać za pierwszy etap testu) oraz podczas bazowania stanowiska po teście. Ostatni siłownik, tj. C9, steruje ramieniem z przyłączami. Badany siłownik po zablokowaniu w gnieździe, opuszczeniu ramienia oraz dojeździe siłowników z przyłączami przedstawiono na rys. 6 .

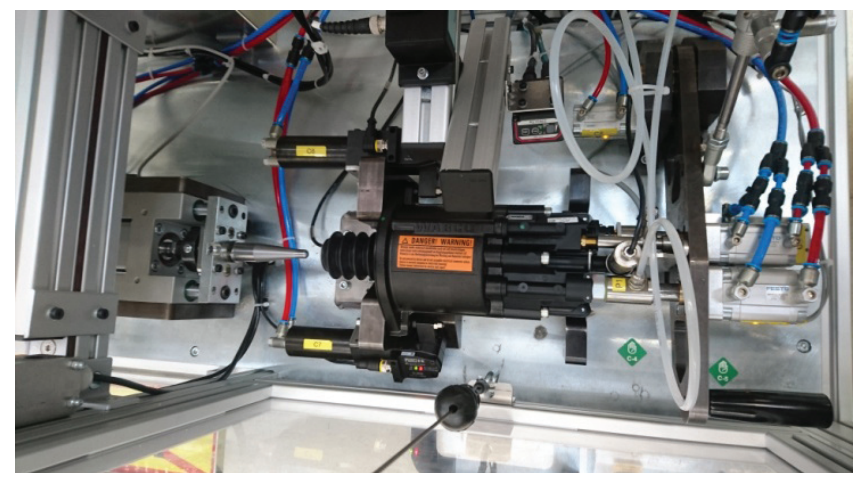

Fig. 6. Tested pneumatic cylinder mounted in the seat

Rys. 6. Badany siłownik pneumatyczny zamocowany w gnieździe

\section{Proces testowania siłownika elektropneumatycznego}

Proces testowania siłowników pneumatycznych obejmuje:

- test komponentów, polegający na sprawdzeniu natężenia prądu na cewkach testowanego siłownika oraz jego „przepracowaniu”;

- test zaworu bezpieczeństwa zamontowanego na tłoku siłownika, polegający na sprawdzeniu jego funkcjonalności poprzez wywarcie odpowiedniego ciśnienia w siłowniku; zadaniem testu jest odpowietrzenie wyrobu w przypadku podania zbyt małego ciśnienia, uniemożliwiającego prawidłową pracę siłownika;

- pierwszy test szczelności, polegający na sprawdzeniu szczelności na przyłączach pneumatycznych P1 i P2. Weryfikowana jest wartość wycieku ciśnienia na przyłączu pneumatycznym P2. Krok ten polega na zasileniu badanego siłownika przez port P1 ciśnieniem o wartości z zakresu 7900 $\div 8100$ mbar, przesterowaniu zaworu 5/3, tak aby przerwać podawanie ciśnienia na port P1, a następnie na pomiarze wycieku ciśnienia na porcie P2;

- drugi test szczelności - analogiczny do testu pierwszego, z tą różnicą, że ciśnienie na porty P1 i P2 jest podawane w odwrotnej kolejności niż podczas testów szczelności;

- test drogi, będący ostatnim etapem - popychacz przesuwa tłok badanego siłownika do pozycji zbliżonej do maksymalnej, a następnie z bardzo małą prędkością wysuwa go dalej, dopóki wartość odczytu z czujnika siły 
(zamontowanego w zespole popychacza) nie przekroczy odpowiedniej wartości. Gdy wartość przekroczy dany próg, to oznacza, że nastąpił nagły wzrost wskazania czujnika siły, co jest tożsame z maksymalnym wysunięciem tłoka badanego siłownika. Następnie popychacz cofa się przed pozycję początkową - tak by nie stykał się z tłokiem. Analogicznie do poprzedniego pomiaru następuje wysuw popychacza $z$ bardzo małą prędkością. Tym razem brana jest pod uwagę wariancja sygnału pochodzącego z czujnika. Gdy wartość wariancji przekroczy dany próg, owa pozycja jest zapisywana jako „tłok wsunięty”. Na koniec, w celu wyznaczeniu skoku tłoka, od wartości tłoka wsuniętego odejmowana jest wartość tłoka wysuniętego. Uzyskany wynik zapisywany jest jako „skok tłoka”.

\section{Przykładowe wyniki testów siłownika}

Analiza MSA [8-12] powtarzalności procesu testowania przyniosła pozytywne wyniki w przypadku wszystkich uwzględnianych parametrów. Warunek krytyczny, jak musi spełnić każda wartość mierzonego parametru, jest opisana wzorem:

$$
c_{\mathrm{gk}}=\frac{0,1 \cdot T-\left|\overline{x_{\mathrm{g}}}-x_{\mathrm{m}}\right|}{3 \cdot S_{\mathrm{g}}}>1,66
$$

gdzie: $T$ - szerokość zakresu tolerancji, $\overline{x_{\mathrm{g}}}-$ średnia wartość wszystkich pomiarów, $x_{\mathrm{m}}$ - średnia wartość przedziału tolerancji, $S_{\mathrm{g}}$ - odchylenie standardowe wszystkich pomiarów.

Im wyższa jest wartość parametru $c_{\mathrm{gk}}$, tym badany parametr jest bardziej powtarzalny.

Dalej zestawiono przykładowe wyniki analizy. Uwzględniono trzydzieści pomiarów pojedynczego siłownika pneumatycznego. Dla skoku tłoka uzyskano $c_{\mathrm{gk}}=6,96$, a rozrzut zmierzonych wartości wyniósł zaledwie 33,7 $\mu \mathrm{m}$ (rys. 7)

Kolejnym parametrem uwzględnianym w analizie powtarzalności jest ciśnienie na porcie P1 w kroku czwartym procedury testowania (rys. 8). Docelowy zakres dla tego parametru wynosi $7800 \div 8200$ mbar. Odchylenie standardowe dla uzyskanych wyników ma wartość 1,73 mbar, natomiast $c_{\mathrm{gk}}=7,96$. To oznacza, że układ pneumatyczny jest bardzo dobrze dostosowany do procesu.

Ostatnim przykładowym parametrem jest siła sprężyny zamontowanej na tłoku (rys. 9). Docelowy zakres tolerancji dla jednego produktu wynosi $\pm 3,5 \mathrm{~N}$. Uzyskano odchylenie standardowe równe $0,57 \mathrm{~N}$ oraz $c_{\mathrm{gk}}=2,15$.

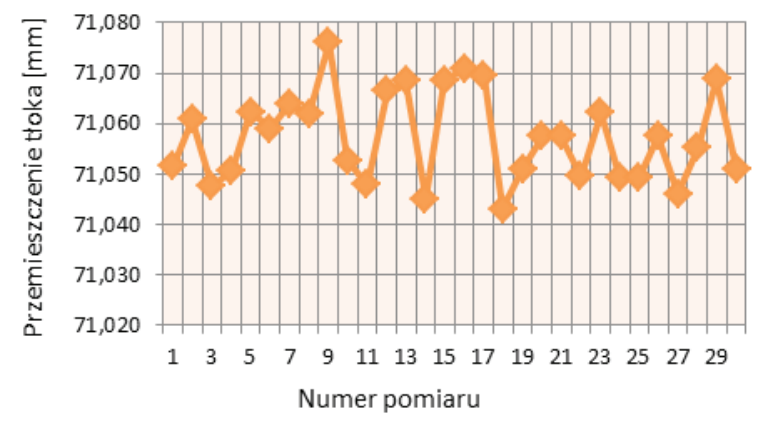

Fig. 7. Measurement results of he piston stroke of the pneumatic cylinder tested

Rys. 7. Wyniki pomiarów skoku tłoka testowanego siłownika pneumatycznego

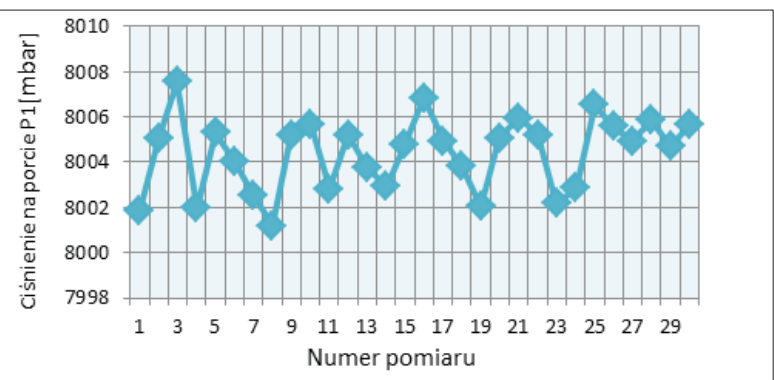

Fig. 8. Measurement results of the pressure at port P1 Rys. 8. Wyniki pomiarów ciśnienia na porcie P1

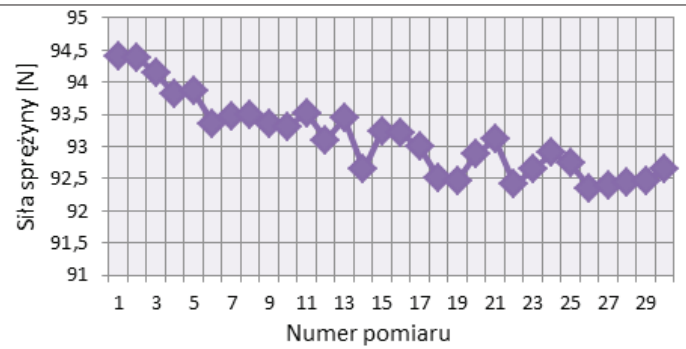

Fig. 9. Results of spring force measurements mounted on the piston of the tested pneumatic cylinder

Rys. 9. Wyniki pomiarów siły sprężyny zamontowanej na tłoku badanego siłownika pneumatycznego

\section{Podsumowanie}

Opisane w artykule stanowisko zostało wdrożone w firmie. Spełniło ono wszystkie wymagania techniczne oraz jest zgodne z normami obowiązującymi w tym przedsiębiorstwie. Na stanowisku przeprowadzono analizę MSA mierzonych parametrów. Uzyskano pozytywne wyniki dla każdego z uwzględnianych etapów procedury testowania. Dzięki temu stanowisko zostało dopuszczone do pracy i włączone w skład linii produkcyjnej siłowników pneumatycznych. Wdrożenie stanowiska w przedsiębiorstwie spowodowało, że wzrósł wskaźnik FPY (first pass yield), określający stosunek sztuk, które przeszły test za pierwszym razem, do liczby wszystkich przebadanych sztuk. W tym przypadku minimalna akceptowalna wartość FPY wynosi $96 \%$.

\section{LITERATURA}

[1] Dychowski P. „Projekt układu sterowania do stanowiska testującego siłowniki pneumatyczne". Praca magisterska. 2019.

[2] Popiol R. „Sprzęgła, skrzynki biegów, wały i półosie napędowe”. Warszawa: Wydawnictwo Komunikacji i Łączności, 2009.

[3] Szenajch W. "Napęd i sterowanie pneumatyczne”. Warszawa: Wydawnictwo Naukowo-Techniczne, 2005.

[4] Osiński Z. „Sprzęgła i hamulce”. Warszawa: Wydawnictwo Naukowe PWN, 1996.

[5] https://truckfocus.pl/technika/7826/koncentryczny-cylinder-wysprze glajacy-conact (dostęp: 9.01.2014)

[6] https://warsztatowiec.info/valeo-sprzegla-ciezarowek (dostęp: 19.02.2018)

[7] https://autokult.pl/1978,hydrauliczne-sterowanie-sprzeglem.

[8] Chenhui Sha, Hui Wang, Saumuy Suriano-Puchala, S. Jack Hu. "Engineering fusion spatial modeling to enable areal measurement system analysis for optical surface metrology". Measurement. 136 (2019): 163-172.

[9] Tsu-Ming Yeh, Jia-Jeng Sun. "Using the Monte Carlo Simulation Methods in Gauge Repeatability and Reproducibility of Measurement System Analysis". Journal of Applied Research and Technology. 11, 5 (2013): 780-796.

[10] Bevilacqua M., Ciarapica F.E., Giacchetta G., Marchetti B. "Implementation of a quality procedure based on Delphi method and the ISO/TS 16949:2009 in the production of stainless steel tubes for automotive exhaust systems". International Journal of Quality \& Reliability Management. 28, 8 (2011): 841-866.

[11] Salman T. Al-Mishari. "Integrating Six-Sigma with other reliability improvement methods in equipment reliability and maintenance applications". Journal of Quality in Maintenance Engineering. 14, 1 (2008): 59-70.

[12] Gijo E.V., Shreeranga Bhat, Jnanesh N.A. "Application of Six Sigma methodology in a small-scale foundry industry". International Journal of Lean Six Sigma. 5, 2 (2014): 193-211. 